\title{
The New Open Economy Macroeconomics of Working Habits
}

\author{
Yunqing Wang1, Qianwen Liư ${ }^{1}$, Bayi Guan², Xinyu Sui² \\ ${ }^{1}$ Financial Research Center, Fudan University, Shanghai, China \\ ${ }^{2}$ Commercial College, Yantai Nanshan University, Yantai, China \\ Email: yqwang82@fudan.edu.cn
}

Received 24 January 2015; accepted 11 February 2015; published 15 February 2015

Copyright (C) 2015 by authors and Scientific Research Publishing Inc.

This work is licensed under the Creative Commons Attribution International License (CC BY). http://creativecommons.org/licenses/by/4.0/

(c) (i) 0pen Access

\begin{abstract}
This paper develops a new open economy macroeconomics model by allowing for habit formation in labor supply. The main findings of our analysis are that 1) an increase in the importance of working habits strengthens the effect of monetary policy shocks on relative consumption, weakens on change in the equilibrium exchange rate, and 2) an increase in the importance of working habits strengthens the response of relative consumption and the equilibrium exchange rate change to fiscal policy shocks.
\end{abstract}

\section{Keywords}

Working Habits, New Open Economy Macroeconomics, Monetary and Fiscal Policy

\section{Introduction}

Similar to consumption habit (Abel [1]) which is widely discussed in macroeconomics and finance, labor supply in habit formation is also very important due to the fact that it plays an important role in determining labor supply. Woittiez and Kapteyn [2] find empirical evidence that habit formation and preference interdependence play an important role in determining female labor supply in the Netherlands. Also, they investigate that habit formation exerts a stronger impact on labor supply than preference interdependence. Kubin and Prinz [3] develop a model with general micro economic framework in order to account for the above empirical results. From the views of work ethics, Faria [4] firstly introduces working habits in a neoclassical growth model and compares its results with a model without habit formation in labor supply.

No study has so far attempted to introduce the hypothesis of working habits into the new open economy macro-economics (NOEM) paradigm, so the main innovation in our exercise is that we elaborate on OR model with working habits. In recent years, NOEM models of type developed by Obstfeld and Rogoff [5] [6] have been as 
the major platform for the analysis of macroeconomic policies in open economies. We use a two-country model in NOEM framework rather than closed-economy endogenous growth or RBC approaches. This allows us to take into account the macroeconomic propagation mechanism of monetary policy as well as fiscal policy in working habit based on benchmark OR model. The other innovation from their paper in our exercise is that we can derive analytical solutions, and use a simple graphical apparatus, which can give us an intuitive explanation, to illustrate our issue rather than numerical simulation.

As the assumption of Faria and Miguela [7], in the paper we postulate that social incentives produce a work ethic determining the amount of work hours for a representative worker, encouraging the worker to supply more labor. In other words, past work forms a stock of habits that elevate worker satisfaction in a hard-worker society such as Japanese economic success up to 1990s (Temin, 1997), so Becker, Grossman and Murphy [8] call "rational addiction" for labor supply.

For brevity, we restrict the attention to the question of how the strength of habit formation affects the response of both relative consumption and the exchange rate to monetary and fiscal policy, particularly in comparison with those illustrated by the benchmark OR model, in which habit-forming labor supply is ignored.

The remainder of this paper is organized as follows. In Section 2, we outline the features of the dynamic optimizing model. In Section 3, we present model results. In Section 4, we make a conclusion.

\section{Model Structure}

\subsection{Households}

The world is populated by a continuum of infinitely-lived households. Every agent being both household and firm is indexed by $z \in[0,1]$. Home agents are located in the interval $[0, \mathrm{n}]$, while foreign agents are on the interval (n, 1]. Total world population is normalized to 1.

In this model with habit forming-labor supply, the utility of a person $\left(U_{t}\right)$ not only depends upon current levels of consumption $\left(C_{t}\right)$, leisure $\left(1-l_{t}\right.$, with $l_{t}$ the labor time supplied) and real balances $\left(M_{t} / P_{t}\right)$, but also depends upon the past work which forms a stock of habits $\left(K_{t}\right)$ as following:

$$
K_{t}=(1-\rho) K_{t-1}+\rho l_{t-1}
$$

where $\rho$ represents the relative importance of work at different times (just like Becker [8], Fuhrer [9]). The higher $\rho$ the more important recent work is for habit, and vice versa.

The domestic agent's utility function can be interpreted as

$$
U_{t}=\sum_{s=t}^{\infty} \beta^{s-t}\left[\log C_{s}+\chi \log \frac{M_{s}}{P_{s}}+k \log \left(1-l_{s}\right)+\psi \log K_{s}\right]
$$

where $0<\beta<1$ is discount factor, and $\chi$ and $\kappa$ are positive parameters. $\psi \geq 0$ is the psychological gratification of working habits in the utility function (see Faria, 2001, 2004). The higher is $\psi$ the larger utility agents can derive due to the presence of working habits. Obviously, our setup will collapse to benchmark OR model when $\psi=0$. For simplicity, we also assume $\rho=1$, which a stock of habits only are decided by the last-term work supply, so the above utility function can be transformed into the following pattern. In what follows we introduce domestic equations. Due to the symmetry of the model, the foreign agents can be assumed to be analogous to domestic equations:

$$
U_{t}=\sum_{s=t}^{\infty} \beta^{s-t}\left[\log C_{s}+\chi \log \frac{M_{s}}{P_{s}}+k \log \left(1-l_{s}\right)+\psi \log l_{s-1}\right]
$$

Subject to the budget constraint

$$
M_{t}+P_{t} B_{t+1}=P_{t}\left(1+r_{t}\right) B_{t}+M_{t-1}+w_{t} l_{t}+\pi_{t}-P_{t} C_{t}-P_{t} T_{t}
$$

where the only asset they trade is a nominal bond denominated in the currency of the domestic country, that we denote with $B_{t} . r_{t}$ is the real interest rate on this bond between $t$ and $t+1 . M_{t}$ denotes nominal money balances held at the beginning of period $t . W_{t}$ is the nominal wage paid to the household in a competitive labor market. $\pi_{t}$ is the household's share of profits from domestic firms. $T_{t}$ denotes lump-sum taxes from the government. 
Let $c(z)$ be a home individual's consumption of product $z$. The consumption index is given by

$$
C=\left[\int_{0}^{1}(c(z))^{\frac{\theta-1}{\theta}}\right]^{\frac{\theta}{\theta-1}}
$$

where $\theta>1$ is the elasticity of substitution between any pair of individual goods. The corresponding price index is

$$
P=\left[\int_{0}^{n} p(z)^{1-\theta} \mathrm{d} z+\int_{n}^{1}\left(e p^{*}(z)\right)^{1-\theta}\right]^{\frac{1}{1-\theta}}
$$

where $p(z)$ is the price of good $\mathrm{z}$ denominated by domestic currency, $p^{*}(z)$ is the foreign currency price of foreign good $z$ and $e$ is the nominal exchange rate which is defined as the price of the foreign currency in terms of the domestic currency. We assume that the law of one price holds. This implies that the home and foreign consumer prices indexes are linked by the purchasing power parity (PPP) relationship $P=P^{*} e$.

Solving the optimization problem presented above yields the following first-order conditions:

$$
\begin{aligned}
C_{t+1} & =\beta\left(1+r_{t+1}\right) C_{t} \\
\frac{M_{t}}{P_{t}} & =\chi C_{t} \frac{1+i_{t+1}}{i_{t+1}} \\
k \frac{1}{1-l_{t}} & =\frac{w_{t}}{P_{t} C_{t}}+\beta \psi \frac{1}{l_{t}}
\end{aligned}
$$

where Equation (3) is a standard Euler equation for optimal consumption. Equation (4) equates the marginal utility of real balances to the opportunity cost in terms of consumption. Deviating from standard labor-leisure trade-off equation, Equation (5) equates the marginal disutility of labor with the marginal positive utility of the real wage plus of a stock of working habits, thereafter called as labor-leisure with working-habit trade-off equation.

\subsection{Government}

The template is used to format your paper and style the text. All margins, column widths, line spaces, and text fonts are prescribed; please do not alter them. You may note peculiarities. For example, the head margin in this template measures proportionately more than is customary. This measurement and others are deliberate, using specifications that anticipate your paper as one part of the entire journals, and not as an independent document. Please do not revise any of the current designations.

It is assumed that there is government spending can be financed through lump-sum taxes or seignorage. The government budget constraint, expressed in per-capita terms, is given by

$$
G_{t}=\frac{M_{t}-M_{t-1}}{P_{t}}+T_{t}
$$

\subsection{Firms}

For simplicity it is assumed that output is equal to labor input. Thus

$$
y_{t}(z)=l_{t}(z)
$$

where $y(z)$ is output of firm $z$.We also assume that each firm enjoys a certain degree of monopolistic power in the production of its differentiated good. Under this assumption, demand for the output of firm $z$ is given by

$$
y_{t}^{d}(z)=\left(\frac{p_{t}(z)}{P_{t}}\right)^{-\theta} C_{t}^{w}
$$

where $C_{t}^{w}$ denotes world aggregate consumption given by $C_{t}^{w}=n C_{t}+(1-n) C_{t}^{*}$. In the absence of price rigidities, the profit maximization process would imply that the price of each differentiated good is given by a simple 
mark-up over wages, according to the equation

$$
p_{t}(z)=\frac{\theta}{\theta-1} w_{t}
$$

\subsection{The Initial Steady State}

We consider an initial steady state where net foreign assets are zero for both countries $\left(B_{0}=B_{0}^{*}=0\right)$. Under this assumption we have, applying the zero subscript to denote the initial steady state:

$$
C_{0}=y_{0}=C_{0}^{*}=y_{0}^{*}=C_{0}^{w}=y_{0}^{w}=\frac{\frac{\theta-1}{\theta}+\beta \psi}{k+\frac{\theta-1}{\theta}+\beta \psi}
$$

It is easy to verify the fact that $\psi$ is increasing function of consumption (output) in steady state. The steadystate consumption (output) will be minimum value under $\psi=0$ case, which reduces to benchmark OR model. Thereafter, the higher $\psi$ the higher is steady-state consumption (output). The intuition behind the results is that agents with working habits will supply more labor, and it results in the increase in output and consumption.

\subsection{Short-Run Nominal Rigidities and Log-Linearization}

We also introduce short-run nominal rigidities in the form of one period preset price in the currency of the producer as in OR model. In terms of notation, in the log-linearized version of the model, we will denote shortrun variables using tildes, and long-run variables using hats. In the short run, nominal producer prices $\tilde{p}(h)$ and $\tilde{p}^{*}(f)$ are predetermined; that is, they are set a period in advance but can be adjusted fully after one period.

In order to solve our model, we should resort to log-linearization. Equations (11)-(20) summarize the log-linearization of the model around the initial steady state presented above.

Due to the symmetry of the model, only the domestic equations, the PPP equation, and the world goods market equilibrium equation are reported. Equations (11)-(20) are log-linearized versions of price index, the Euler equation, the short- and long-run money demand equations, the labor-leisure with working-habit trade-off equation, the demand equation, the short-and long run current account equations, the PPP equation and the world goods market equilibrium condition.

$$
\begin{gathered}
\tilde{P}=n \tilde{p}(h)+(1-n)\left(\tilde{e}+\tilde{p}^{*}(f)\right) \\
\hat{C}=\tilde{C}+\frac{\delta}{1+\delta} \tilde{r} \\
\tilde{M}-\tilde{P}=\tilde{C}-\frac{\tilde{r}}{1+\delta}-\frac{\hat{P}-\tilde{P}}{\delta} \\
\hat{P}=\hat{M}-\hat{C} \\
\left(\beta \psi+\frac{\theta-1}{\theta}+k-\Lambda_{1}\right) \hat{y}=\Lambda_{1}(\hat{p}(h)-\hat{P}-\hat{C}) \\
\tilde{y}=-\theta(\tilde{p}(h)-\tilde{P})+\tilde{C}^{w}+\tilde{G}^{w} \\
\hat{B}=\tilde{y}-\tilde{C}-(1-n) \tilde{e}-\tilde{G} \\
\hat{C}=\delta \hat{B}+\hat{p}(h)-\hat{P}+\hat{y}-\hat{G} \\
\tilde{e}=\tilde{P}-\tilde{P}^{*} \\
\hat{C}^{w}=\left[\begin{array}{c}
\Lambda_{1} \\
\beta \psi+\frac{\theta-1}{\theta}+k
\end{array}\right] \hat{G}^{w}, \hat{y}^{w}=\left[\frac{\Lambda_{1}}{\beta \psi+\frac{\theta-1}{\theta}+k}\right] \hat{G}^{w}
\end{gathered}
$$


Equations (11)-(20) note: $\delta \equiv i_{0}=\frac{1-\beta}{\beta} ; \Lambda_{1} \equiv \frac{k(\theta-1)}{\theta-1+\beta \psi \theta}>0$

\section{The Results}

In this section, we consider macroeconomic effects of monetary and fiscal policy in the formation of working habits OR model.

\subsection{Two Basic Relationships of the Model}

Following Obstfeld and Rogoff's graphical analysis, we derive the following MM and GG schedules, respectively:

$$
\begin{gathered}
\tilde{e}=\left(\hat{M}-\hat{M}^{*}\right)-\left(\tilde{C}-\tilde{C}^{*}\right) \\
\tilde{e}=\Lambda_{3}\left(\tilde{C}-\tilde{C}^{*}\right)+\frac{1}{(\theta-1)}\left[\left(\tilde{G}-\tilde{G}^{*}\right)+\frac{1}{\delta}\left(\hat{G}-\hat{G}^{*}\right)\right]
\end{gathered}
$$

where

$$
\Lambda_{2} \equiv \theta\left(\beta \psi+\frac{\theta-1}{\theta}+k-\Lambda_{1}\right)+\Lambda_{1} \succ 0, \Lambda_{3} \equiv \frac{1}{\theta-1}\left[\frac{1}{\delta}\left(1+\frac{(\theta-1) \Lambda_{1}}{\Lambda_{2}}\right)+1\right]>0
$$

\subsection{Monetary Shock}

To simplify, we look at monetary and fiscal shocks separately, thereby assuming temporarily that $\hat{G}=\hat{G}^{*}=\tilde{G}=\tilde{G}^{*}=0$. In particular, the MM schedule for this case is still given by Equation (21), but the GG schedule Equation (22) arrive at the following equation:

$$
\tilde{e}=\Lambda_{3}\left(\tilde{C}-\tilde{C}^{*}\right)
$$

The effects of expansionary monetary shocks (i.e. $\hat{M}-\hat{M}^{*}>0$ ) are represented in Figure 1 . Due to the fact that $\Lambda_{3}$ is decreasing function of $\psi^{1}$, the new equilibrium in the case of OR model with working habits will arrive at the new intersection point EQ2 compared to EQ1 in the case of the benchmark OR model without working habits (i.e. $\psi=0$ ), according to arrow sign in Figure 1. This shows that the level of relative consumption will be higher while the level of the depreciation of domestic currency will be lower.

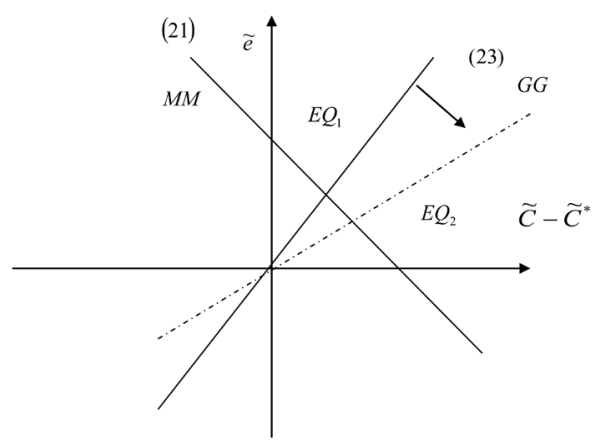

Figure 1. An unanticipated domestic relative domestic money supply increase associated with working habits.

${ }^{1}$ Obviously, $\frac{\Lambda_{1}}{\Lambda_{2}}>0$, we just need to poof $\frac{\Lambda_{1}}{\Lambda_{2}}$ is decreasing function of $\psi$, so we can derive:

$\frac{\Lambda_{1}}{\Lambda_{2}}=\frac{\Lambda_{1}}{\beta \psi \theta+\theta-1+k \theta-(\theta-1) \Lambda_{1}}=\frac{k(\theta-1)}{(\beta \psi \theta+\theta-1+k \theta)(\theta-1+\beta \psi \theta)-k(\theta-1)^{2}}$. It is easy to know the result holds from the above expression. 
The intuition for the result that domestic consumption increases more compared to the foreign consumption is that the higher $\psi$, the larger the psychological gratification of working habits, the more labor supply in proportional to output is for both countries agents, the increase in output associated with the increase in consumption, but asymmetric monetary shocks elevate more domestic consumption than its foreign counterpart. We can conclude that the larger is importance of working habits, the more flexible is the response of relative consumption levels to a monetary shock.

Furthermore, the lower magnitude of domestic depreciation is to restore equilibrium in the money market due to the more increase in relative consumption caused by the presence of working habits.

\subsection{Fiscal Shock}

Now, we restrict our attention to government spending shocks, in analogy to the above monetary shocks case, thus abstracting from monetary changes by assuming that $\hat{M}=\hat{M}^{*}=0$. The GG schedule Equation (22) holds. Instead of Equation (21), the expression

$$
\tilde{e}=-\left(\tilde{C}-\tilde{C}^{*}\right)
$$

describes the new MM schedule, which passes through the origin in Figure 2. Figure 2 illustrates the effects of expansionary fiscal shocks (including a permanent or temporary increase in home government spending relative to foreign counterpart).

As we mention above, the higher $\psi$ results in the lower slope of GG schedule, while keeping the vertical intercept unchanged. Compared to the intersection point EQ1 without working habits in benchmark OR case, the new equilibrium will arrive at the new intersection point EQ2 in the presence of working habits. From Figure 2, home consumption falls more relative to foreign consumption while the level of domestic currency depreciation will be higher.

Intuitively, domestic residents are paying for the government spending more, but a government's spending equally falls on home and foreign goods, which doesn't exist home-product bias, so home country people consume less with respect to its foreign. When there are habit formations for labor supply, the habit formations enhance the mechanism due to our parameters setup. Because the relative consumption change lowers the relative demand for home money, nominal exchange rate rises more.

\section{Conclusions}

In this paper we have analyzed the impact of introducing habit formation in labor supply in OR model and compared its outcome in terms of monetary policy and fiscal policy with a model in the absence of habit formation. We make some progress towards a model that meets the benchmark OR model. It does so by including a particular form of non-time-separability in the utility function, namely "habit formation", or the assessment by

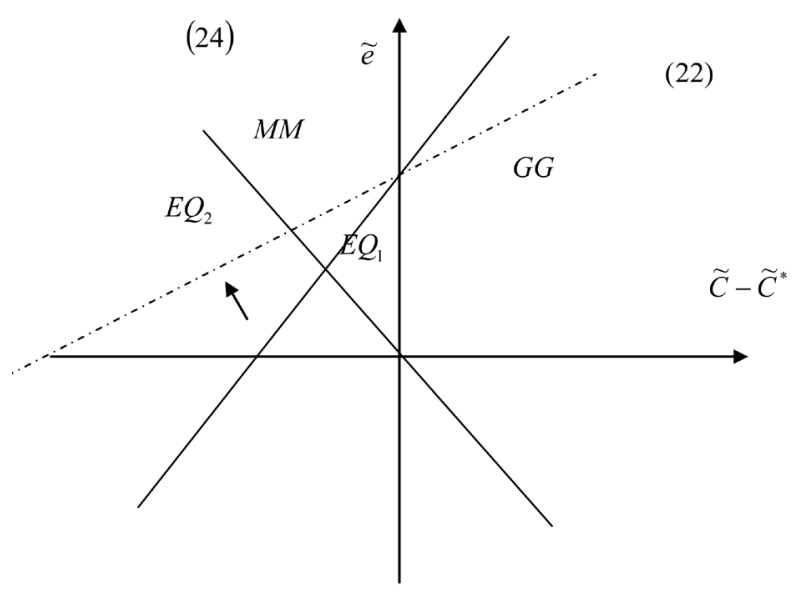

Figure 2. A relative domestic government spending increase associated with working habits. 
households of utility relative to a habit level of labor. Our results are important since in the future they help to explain differences in the long-run performance of economies with different social incentives towards work owing to cultural, religious and economic organization factors as evidenced in the empirical literature.

Finally, we just restrict our attention on theoretical aspects of the NOEM model with habit formation of labor supply, so whether the results of this paper are consistent with empirical evidence or not put in the future research.

\section{Acknowledgements}

The research work was supported by the MOE (Ministry of Education in China) Project of Humanities and Social Sciences for the Youth (Project No.14YJC790129), China Postdoctoral Science Foundation (2014 M550205).

\section{References}

[1] Abel, A.B. (1990) Asset Prices under Habit Formation and Catching up with the Joneses. American Economic Review, 80, 38-42.

[2] Woittiez, I. and Kapteyn, A. (1998) Social Interactions and Habit Formation in a Model of Female Labor Supply. Journal of Public Economics, 70, 185-205. http://dx.doi.org/10.1016/S0047-2727(98)00021-8

[3] Kubin, I. and Prinz, A. (2002) Labor Supply with Habit Formation. Economics Letters, 81, 75-79. http://dx.doi.org/10.1016/S0165-1765(01)00595-X

[4] Faria, J.R. (2001) Habit Formation in a Monetary Growth Model. Economics Letters, 73, 51-55. http://dx.doi.org/10.1016/S0165-1765(01)00464-5

[5] Obstfeld, M. and Rogoff, K. (1995) Exchange Rate Dynamics Redux. Journal of Political Economics, 103, 624-660. http://dx.doi.org/10.1086/261997

[6] Obstfeld, M. and Rogoff, K. (1996) Foundations of International Macroeconomics. MIT Press, Cambridge.

[7] Faria, J.R. and León-Ledesma, M.A. (2004) Habit Formation, Work Ethics and Technological Progress. The Manchester School, 72, 403-413. http://dx.doi.org/10.1111/j.1467-9957.2004.00399.x

[8] Becker, G.S., Grossman, M. and Murphy, K.M. (1991) Rational Addiction and the Effect of Price on Consumption. American Economic Review, 81, 237-251.

[9] Fuhrer, J.C. (2000) Habit Formation in Consumption and Its Implications for Monetary-Policy Models. American Economic Review, 90, 367-390. http://dx.doi.org/10.1257/aer.90.3.367 
Scientific Research Publishing (SCIRP) is one of the largest Open Access journal publishers. It is currently publishing more than 200 open access, online, peer-reviewed journals covering a wide range of academic disciplines. SCIRP serves the worldwide academic communities and contributes to the progress and application of science with its publication.

Other selected journals from SCIRP are listed as below. Submit your manuscript to us via either submit@scirp.org or Online Submission Portal.
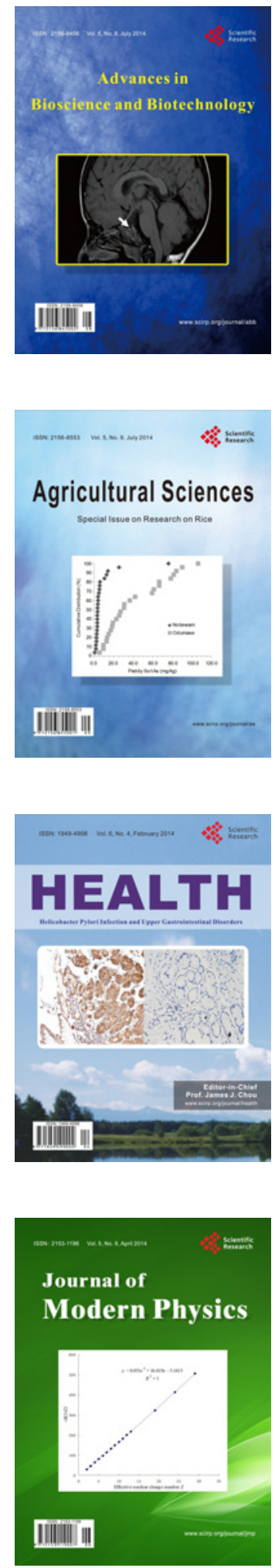
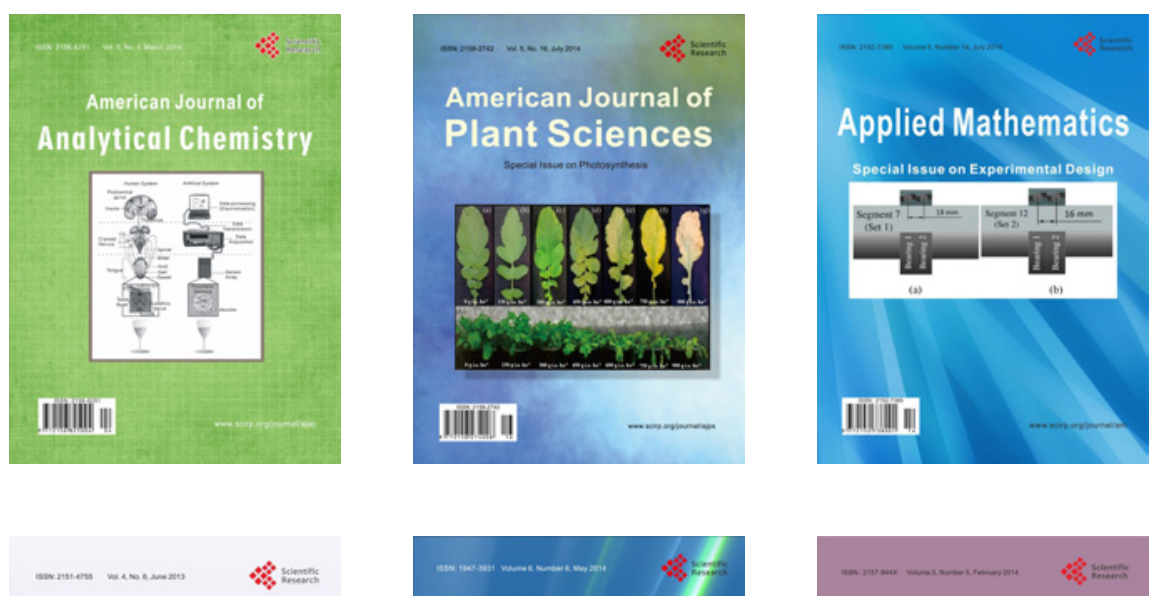

Creative Education
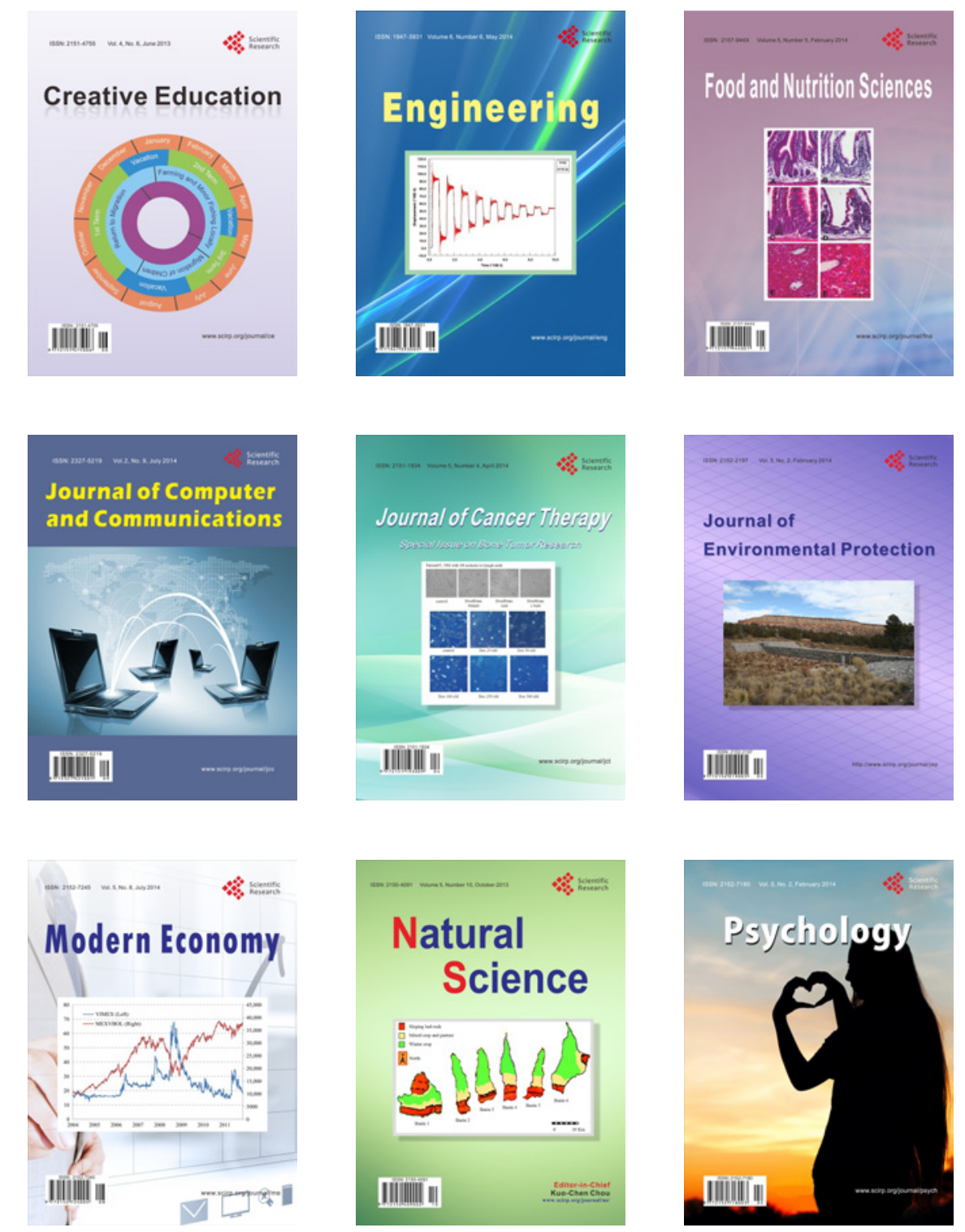